\title{
Haliea mediterranea sp. nov., a marine gammaproteobacterium
}

\author{
Teresa Lucena, ${ }^{1,2}$ Javier Pascual, ${ }^{1}$ Esperanza Garay, ${ }^{1,2}$ David R. Arahal, ${ }^{1,2}$ \\ M. Carmen Macián ${ }^{2}$ and María J. Pujalte ${ }^{1,2}$
}

Correspondence
María J.Pujalte
Maria.J.Pujalte@uv.es

The genus Haliea was described recently, with one species, Haliea salexigens (Urios et al., 2008), to accommodate a marine strain isolated from seawater of the Mediterranean Sea; a second species, Haliea rubra (Urios et al., 2009), was later isolated from the same habitat. These organisms belong to a branch of marine gammaproteobacteria that corresponds to the so-called NOR5 clade. This clade includes more than 500 16S rRNA gene sequences from public databases but, until recently, it has contained very few cultured and taxonomically characterized representatives (Yan et al., 2009). The NOR5 clade is of particular interest because of the recent description of a member, Congregibacter litoralis $\mathrm{KT} 71^{\mathrm{T}}$, that represents the first cultured photosynthetic aerobic gammaproteobacterium (Spring et al., 2009). Until now, bacteriochlorophyll (Bchl) $a$-producing, strict aerobes were confined to the alphaproteobacteria, but the finding of C. litoralis $\mathrm{KT}^{\mathrm{T}}{ }^{\mathrm{T}}$ has extended the distribution to marine gammaproteobacteria. This facultative photoheterotroph is the nearest taxon to $H$. rubra in terms of sequence similarity.

Strain $7 \mathrm{SM} 29^{\mathrm{T}}$ was isolated from a seawater sample obtained not far from the area from which $H$. salexigens $3 \mathrm{X} / \mathrm{A} 02 / 235^{\mathrm{T}}$ was isolated, at $10 \mathrm{~m}$ depth off the coast of

Abbreviation: Bchl, bacteriochlorophyll.

The GenBank/EMBL/DDBJ accession number for the $16 \mathrm{~S}$ rRNA gene sequence of strain $7 \mathrm{SM} 29^{\top}$ is $\mathrm{FN} 398053$.
Vinaroz, Castellón, Spain, in July 1989. The seawater was decimally diluted in sterile seawater, plated on marine agar (MA; Difco) and incubated at $20-22{ }^{\circ} \mathrm{C}$ for up to 10 days. Isolated colonies on plates of the highest positive inoculum dilution were streaked on the same medium and subcultured under the same conditions until a pure culture was obtained. Strain $7 \mathrm{SM} 29^{\mathrm{T}}$ was maintained as cells suspended in marine broth (MB; Difco) and $20 \%$ glycerol at $-80{ }^{\circ} \mathrm{C}$. Strain $7 \mathrm{SM} 29^{\mathrm{T}}$ was included in a numerical taxonomic study of several aerobic, marine, Gram-negative bacteria obtained from similar samples and clustered in an unidentified phenon of fairly unreactive strains (phenon 41; Ortigosa et al., 1994). Recently, the strain has been recovered as part of a project to characterize a collection of unidentified marine isolates kept at the Department of Microbiology and Ecology, University of Valencia. Strain $7 \mathrm{SM} 29^{\mathrm{T}}$ was submitted to partial $16 \mathrm{~S}$ rRNA gene sequencing and BLAST searches in public sequence databases indicated that the sequence of strain $7 \mathrm{SM} 29^{\mathrm{T}}$ had less than $95 \%$ similarity to all sequences of formally described bacterial species, with $H$. salexigens as the closest recognized relative. The low sequence similarity suggested that strain $7 \mathrm{SM} 29^{\mathrm{T}}$ could represent a novel taxon; thus, we performed a complete characterization de novo.

Strain $7 \mathrm{SM} 29^{\mathrm{T}}$ was grown routinely on MA or in $\mathrm{MB}$ at $25-28{ }^{\circ} \mathrm{C}$ for $48-72 \mathrm{~h}$ to prepare inocula and samples. Unless otherwise stated, all media were supplemented with 
half-strength artificial seawater (ASW; $400 \mathrm{mM} \mathrm{NaCl}$, $100 \mathrm{mM} \mathrm{MgSO}_{4} .7 \mathrm{H}_{2} \mathrm{O}, 20 \mathrm{mM} \mathrm{KCl}$ and $20 \mathrm{mM}$ $\mathrm{CaCl}_{2} \cdot \mathrm{H}_{2} \mathrm{O}$ ). Suspension media for microscopic observations or miniaturized testing were also supplemented with ASW. The API 20NE, API ZYM (bioMérieux) and GN2 (Biolog) tests were performed in duplicate.

Strain $7 \mathrm{SM} 29^{\mathrm{T}}$ on $\mathrm{MA}\left(28^{\circ} \mathrm{C}, 48 \mathrm{~h}\right)$ formed regular, rounded, translucent colonies with entire edges and a slightly yellow, non-diffusible pigmentation. It did not show swarming motility. No luminescence was observed. The ability to grow at different temperatures was tested on MA at 4 and $15{ }^{\circ} \mathrm{C}$ ( 15 days) and at $28,37,40$ and $45{ }^{\circ} \mathrm{C}$ $(48 \mathrm{~h})$. The strain was able to grow at $15-40{ }^{\circ} \mathrm{C}$, but not at 4 or $45^{\circ} \mathrm{C}$. Ion requirements were tested on media containing $1 \%$ peptone, $0.3 \%$ yeast extract and $1.2 \%$ bacteriological agar with and without $2 \%(\mathrm{w} / \mathrm{v}) \mathrm{NaCl}$. Strain $7 \mathrm{SM} 29^{\mathrm{T}}$ did not grow without $\mathrm{NaCl}$ and grew slowly after 4 days on $\mathrm{NaCl}$-supplemented medium. The range of salinity for growth was tested on MA as reported previously (Macián et al., 2005). The strain showed good growth with $0.35-12 \%$ total salinity, weak and slow growth with $15 \%$ salinity and no growth with $18 \%$ salinity or higher. Strain $7 \mathrm{SM} 29^{\mathrm{T}}$ was oxidase- and catalase-positive, able to reduce nitrate to nitrite (no gas) in nitrate broth and with API 20NE strips and unable to ferment glucose on $\mathrm{O} / \mathrm{F}$ medium. Extracellular hydrolysis of casein, DNA, starch and Tween 80 was detected after 1 week on MA-based media, although the halo of hydrolysis was usually small. Gelatin was hydrolysed in MB supplemented with $12 \%$ $(\mathrm{w} / \mathrm{v})$ gelatin (liquefaction of the aerobic zone of the tube) but API 20NE gave a negative response to this test. The results with API 20NE, API ZYM and Biolog GN2 are reported in the species description and Table 1.

Cell morphology, motility and flagellar arrangement were observed on wet mounts by phase-contrast microscopy. Cell size was determined by using scanning electron microscopy at the Servicio Central de Soporte a la Investigación Experimental (University of Valencia). Samples were examined in a Hitachi S-4100 field emission scanning microscope with a 7-15 $\mathrm{mm}$ working distance and at an acceleration voltage of $10 \mathrm{kV}$. Pictures were stored digitally and processed using the software Quantax 200. Cells of strain $7 \mathrm{SM} 29^{\mathrm{T}}$ are small, straight, regular bacilli, $0.4-0.5 \mu \mathrm{m}$ wide and $1.1-1.3 \mu \mathrm{m}$ long with rounded ends, single or in pairs (Fig. 1), motile by means of one, two or three monopolar flagella, as seen after flagellar staining with the method of Heimbrook et al. (1989). Occasionally, the strain showed a jerky type of motility that might be considered twitching motility. The cells did not clump or form evident aggregates, although extracellular

\section{Table 1. Differential characteristics among strains of the genera Haliea and Congregibacter}

Strains: 1, Haliea mediterranea sp. nov. 7SM29 ${ }^{\mathrm{T}}$ (data from this study); 2, H. salexigens 3X/A02/235 ${ }^{\mathrm{T}}$ (Urios et al., 2008); 3, H. rubra CM41_15a ${ }^{\mathrm{T}}$ (Urios et al., 2009); 4, C. litoralis $\mathrm{KT}^{\mathrm{T}}{ }^{\mathrm{T}}$ (Spring et al., 2009). +, Positive; w, weak; -, negative; ND, no data available. All strains contained ubiquinone Q-8.

\begin{tabular}{|c|c|c|c|c|}
\hline Characteristic & 1 & 2 & 3 & 4 \\
\hline Motility/flagella & $+/ 3$ polar & $+/ 1$ polar & $-1-$ & $+/ 1-2$ subpolar \\
\hline Bchl $a$ production & - & ND & ND & + \\
\hline \multicolumn{5}{|l|}{ Growth at/with: } \\
\hline $40{ }^{\circ} \mathrm{C}$ & + & - & + & - \\
\hline Hydrolysis of casein, gelatin, starch & + & ND & ND & - \\
\hline \multicolumn{5}{|l|}{ Utilization of: ${ }^{\star}$} \\
\hline L-Alanine & + & - & - & + \\
\hline$\alpha$-D-Glucose & - & - & + & - \\
\hline Glycerol & - & + & - & + \\
\hline Succinate & - & + & - & + \\
\hline Polar lipids $\dagger$ & PG, DPG, PE, 2 AL, GL & PG, DPG, AL & $\mathrm{ND}$ & PG, PE, PL \\
\hline DNA G $+C$ content $(\mathrm{mol} \%)$ & 62.1 & 61.4 & 64.8 & 57.8 \\
\hline
\end{tabular}

${ }^{\star}$ Data were taken from the Biolog GN2 system for columns 1-3 and from growth on sole carbon sources for columns 1 and 4. $\nmid$ DPG, Diphosphatidylglycerol; PE, phosphatidylethanolamine; PG, phosphatidylglycerol; AL, unidentified aminolipid; GL, atypical glycolipid; PL, unidentified phospholipid. 

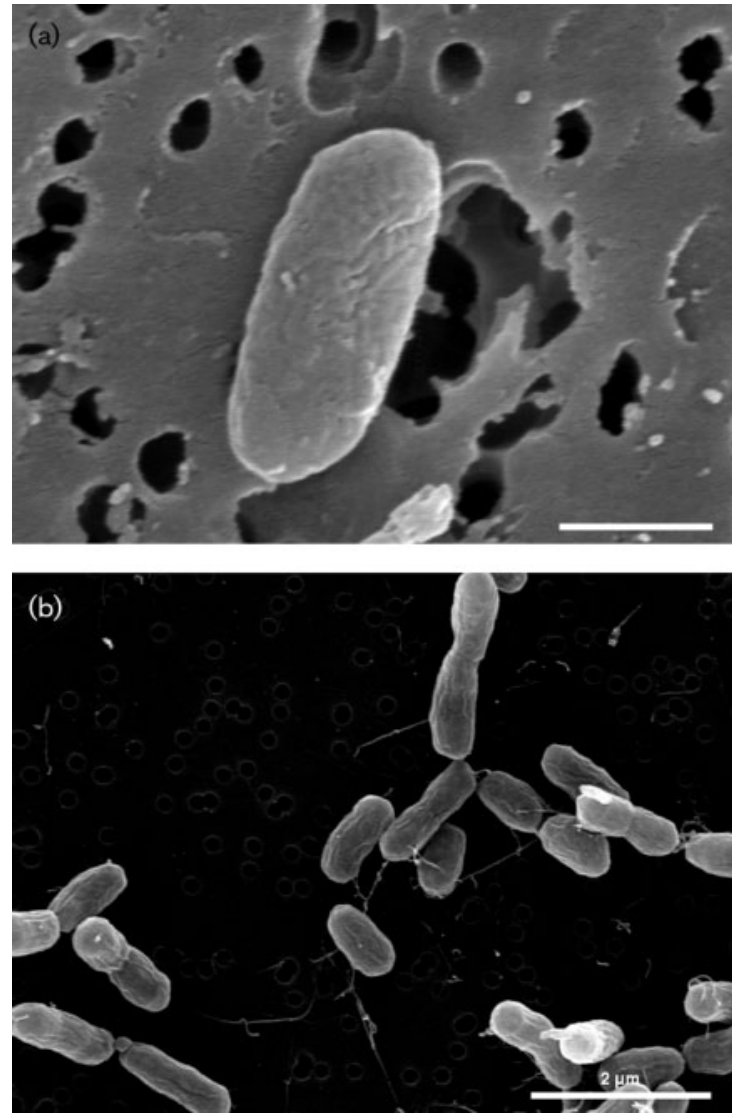

Fig. 1. Scanning electron micrographs showing the cell morphology of strain $7 \mathrm{SM} 29^{\top}$. Dividing cells can also be discerned. Bars, $500 \mathrm{~nm}$ (a) and $2 \mu \mathrm{m}$ (b).

filaments and material are seen in photomicrographs of pairs and short chains of cells. Cell division is by binary fission. The strain was Gram-negative and cells lysed readily when suspended in $3 \%(\mathrm{w} / \mathrm{v}) \mathrm{KOH}$ solution.

Carbon sources for growth were tested on Baumann's basal medium [BMA; $50 \mathrm{mM}$ Tris/HCl (pH 7.5), $19 \mathrm{mM}$ $\mathrm{NH}_{4} \mathrm{Cl}, 0.33 \mathrm{mM} \mathrm{K}_{2} \mathrm{HPO}_{4} \cdot 3 \mathrm{H}_{2} \mathrm{O}, 0.1 \mathrm{mM} \mathrm{FeSO} \cdot 7 \mathrm{H}_{2} \mathrm{O}$, $1.3 \%$, w/v, purified agar (Oxoid), half-strength ASW; Baumann \& Baumann, 1981] in three independent trials. The strain grew readily on medium supplemented with $0.5 \%$ yeast extract, but grew very slowly with sole carbon sources, showing no evident growth after 7 days. Carbon sources that supported growth after 15 days of incubation are given in the species description and Table 1. The pigmentation remained pale yellow during growth with single carbon sources.

To determine the ability of strain $7 \mathrm{SM} 29^{\mathrm{T}}$ to produce Bchl $a$ when grown on poor or minimal medium, cellular acetone extracts were obtained from cells grown in the dark on BMA plates containing a carbon source that supported growth (such as putrescine, acetate or propionate). The absorbance spectra of the extracts were analysed using a
Table 2. Cellular fatty acid profiles of strain $7 \mathrm{SM} 29^{\top}$ and its closest phylogenetic neighbours

Strains: 1, Haliea mediterranea sp. nov. $7 \mathrm{SM} 29^{\mathrm{T}}$ (data from this study); 2 , H. salexigens $3 \mathrm{X} / \mathrm{A} 02 / 235^{\mathrm{T}}$ (Urios et al., 2008); 3, H. rubra CM41_15a $\mathrm{a}^{\mathrm{T}}$ (Urios et al., 2009); 4, C. litoralis KT71 ${ }^{\mathrm{T}}$ (Spring et al., 2009). Values are percentages of total fatty acids. All fatty acid methyl ester profiles correspond to those of cells grown under aerobiosis; not detected.

\begin{tabular}{|ccccc|}
\hline Cellular fatty acid & $\mathbf{1}$ & $\mathbf{2}$ & $\mathbf{3}$ & $\mathbf{4}$ \\
\hline Hydroxy & & & & \\
$\mathrm{C}_{9: 0} 3-\mathrm{OH}$ & - & - & - & 0.5 \\
$\mathrm{C}_{10: 0} 3-\mathrm{OH}$ & 0.8 & 1.8 & - & 2.1 \\
$\mathrm{C}_{11: 0} 3-\mathrm{OH}$ & 2.0 & 3.3 & - & 0.5 \\
iso- $\mathrm{C}_{11: 0} 3-\mathrm{OH}$ & - & 3.3 & - & 0.1 \\
$\mathrm{C}_{12: 0} 3-\mathrm{OH}$ & 1.0 & 1.1 & - & 0.4 \\
$\mathrm{C}_{12: 0} 2-\mathrm{OH}$ & - & - & 1.1 & - \\
$\mathrm{C}_{12: 1} 3-\mathrm{OH}$ & - & - & 3.5 & - \\
Saturated $_{a 10}$ & & & & \\
$\mathrm{C}_{10: 0}$ & 0.8 & - & - & 0.5 \\
$\mathrm{C}_{11: 0}$ & 1.5 & 1.0 & - & 1.0 \\
$\mathrm{C}_{12: 0}$ & 1.1 & 1.6 & - & 2.2 \\
$\mathrm{C}_{13: 0}$ & 1.8 & 1.3 & - & 1.0 \\
$\mathrm{C}_{14: 0}$ & 2.5 & 1.3 & 0.7 & 2.0 \\
$\mathrm{C}_{15: 0}$ & - & 4.5 & 1.2 & 4.9 \\
$\mathrm{C}_{16: 0}$ & 11.2 & 2.0 & 13.0 & 5.4 \\
$\mathrm{C}_{17: 0}$ & 7.5 & 9.3 & 1.0 & 3.1 \\
$\mathrm{C}_{18: 0}$ & 0.3 & - & 0.7 & 0.6 \\
$\mathrm{Unsaturated}$ & & & & \\
$\mathrm{C}_{15: 1} \omega 6 c$ & 0.9 & 5.8 & 0.3 & 2.0 \\
$\mathrm{C}_{16: 1} \omega 6 c$ & - & - & - & 6.5 \\
$\mathrm{C}_{16: 1} \omega 7 c$ & 17.2 & 21.2 & 30.5 & 23.1 \\
$\mathrm{C}_{17: 1} \omega 6 c$ & - & 2.7 & 1.1 & 2.8 \\
$\mathrm{C}_{17: 1} \omega 8 c$ & 19.0 & 23.9 & 2.0 & 8.1 \\
$\mathrm{C}_{18: 1} \omega 7 c$ & 22.6 & 17.5 & 40.2 & 29.7 \\
${ }^{10}$ & & & & \\
\hline
\end{tabular}

Beckman Coulter DU-800 spectrophotometer, as described by Takaichi et al. (1991). The absorbance spectrum of strain $7 \mathrm{SM} 29^{\mathrm{T}}$ revealed no bacteriochlorophyll peak.

Analyses of respiratory quinones and polar lipids were carried out by the Identification Service of the DSMZ and Dr B. J. Tindall (DSMZ). Strain $7 \mathrm{SM} 29^{\mathrm{T}}$ had a ubiquinone (Q-8) system and the polar lipids included phosphatidylglycerol, diphosphatidylglycerol and phosphatidylethanolamine, two unidentified aminolipids and an atypical glycolipid. Major cellular fatty acids and the DNA G + C content were determined by the Identification Service of the DSMZ after incubation on MA at $28{ }^{\circ} \mathrm{C}$ for $48 \mathrm{~h}$. The results are presented in Tables 1 and 2. Monounsaturated 16-18-carbon fatty acids were the most abundant and $\mathrm{C}_{11: 0} 3-\mathrm{OH}$ was the major hydroxylated fatty acid. The DNA G + C content was $62.1 \mathrm{~mol} \%$.

The almost-complete 16S rRNA gene sequence of the strain $7 \mathrm{SM} 29^{\mathrm{T}}$ was obtained by PCR amplification followed by direct sequencing using primers $616 \mathrm{~V}$ (forward) and 699R (reverse), as described by Arahal et al. (2008) to target about 


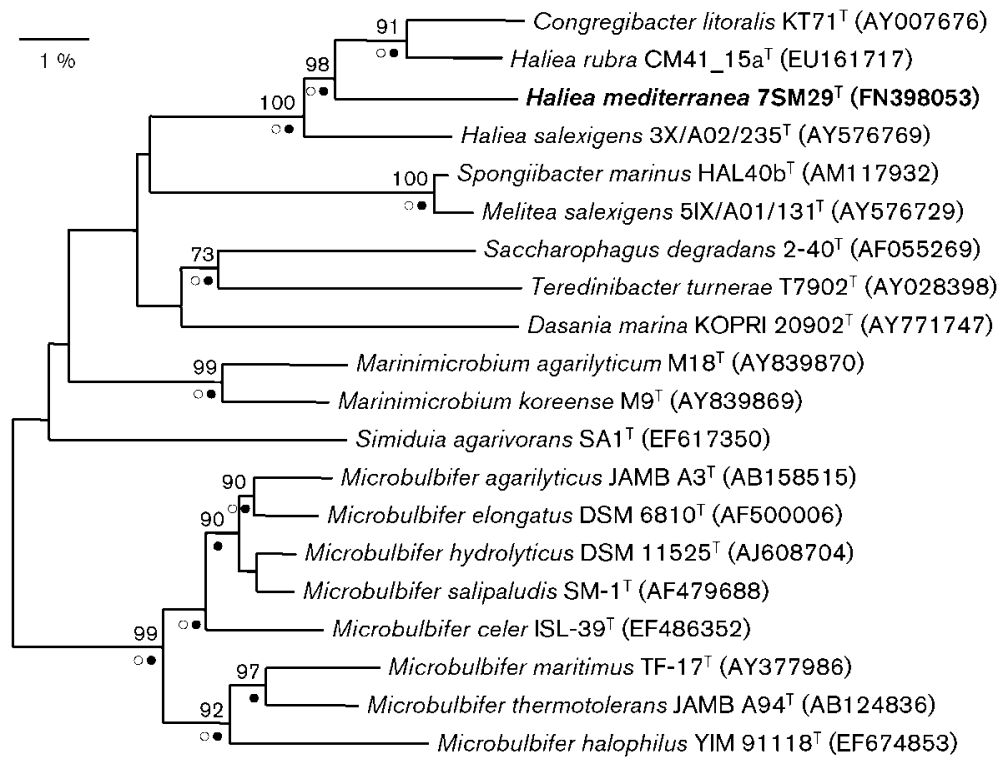

Fig. 2. Neighbour-joining phylogenetic tree based on almost-complete 16S rRNA gene sequences from strain $7 \mathrm{SM} 29^{\top}$ and closely related strains. Bootstrap values (>70\%) based on 1000 resamplings are shown as percentages at branch nodes. Circles indicate that corresponding nodes were recovered in trees generated with the maximum-likelihood method (filled circles) and the maximumparsimony method (open circles). Bar, 1 substitution per 100 nucleotide positions.

1000 nt close to the $5^{\prime}$ end and primers P609D (forward, 5' GGMTTAGATACCCBDGTA-3') and P1525R (reverse, 5'-WAGGAGGTRATCCADCC-3'), from Invitrogen/Life Technologies, to target positions 785-802 and 1525-1541, respectively (Escherichia coli numbering). The manually corrected sequence was compared with public sequences in the EMBL database using the BLAST program (National Center for Biotechnology Information; http://ncbi.nlm.nih. gov/). Related sequences were analysed further using the ARB package (Ludwig et al., 2004; http://www.arb-home.de). Sequence alignments were further corrected manually using the ARB EDIT sequence editor. Phylogenetic analysis using alternative treeing methods (maximum-parsimony, maximum-likelihood and distance matrix) and data subsets were performed using the appropriate ARB tools (Ludwig et al., 1998). Fig. 2 shows the results of the phylogenetic analysis. Strain $7 \mathrm{SM} 29^{\mathrm{T}}$ always clustered in a well-defined clade with the two Haliea type strains and C. litoralis $\mathrm{KT}^{\mathrm{T}}{ }^{\mathrm{T}}$. The sequence of strain $7 \mathrm{SM} 29^{\mathrm{T}}$ had the highest $16 \mathrm{~S}$ rRNA gene sequence similarity to those of $H$. salexigens $3 \mathrm{X} / \mathrm{A} 02 / 235^{\mathrm{T}}$ and $H$. rubra $\mathrm{CM}_{4} 1^{\mathrm{T}}$ (95.0 and $95.2 \%$, respectively) and to the recently described C. litoralis $\mathrm{KT}^{\mathrm{T}}{ }^{\mathrm{T}}(94.8 \%)$. Low sequence similarities were observed between strain $7 \mathrm{SM} 29^{\mathrm{T}}$ and its next closest phylogenetic neighbours, Spongiibacter marinus HAL40b ${ }^{\mathrm{T}}$ (91.2\%) and Melitea salexigens 5IX/A01/ $131^{\mathrm{T}}(90.7 \%)$. All of the other sequences included in Fig. 2 had less than $91 \%$ similarity to that of strain $7 \mathrm{SM} 29^{\mathrm{T}}$.

It can be concluded that strain $7 \mathrm{SM} 29^{\mathrm{T}}$ represents a novel taxon in the vicinity of the genus Haliea. In light of the low $16 \mathrm{~S}$ rRNA gene sequence similarity, this novel taxon could be considered a novel species of Haliea or Congregibacter or even of a novel genus close to both. The phylogenetic analysis suggests a position for strain $7 \mathrm{SM} 29^{\mathrm{T}}$ in the genus Haliea and also points to the possibility of reclassifying $C$. litoralis $\mathrm{KT}^{\mathrm{T}} \mathrm{T}^{\mathrm{T}}$ in the same genus. According to the chemotaxonomic and phenotypic data, the resemblance of strain $7 \mathrm{SM} 29^{\mathrm{T}}$ to the two Haliea species is strong enough to consider it a member of this genus. The $\mathrm{G}+\mathrm{C}$ content of strain $7 \mathrm{SM} 29^{\mathrm{T}}(62.1 \mathrm{~mol} \%)$ is within the range reported for the genus Haliea (61.4-64.8 mol\%) and the quinone composition, lipid and fatty acid profiles, enzyme activities and nutritional preferences for carbon sources are also in agreement with the genus description (Tables 1 and 2). Distinctive features of strain $7 \mathrm{SM} 29^{\mathrm{T}}$ are the temperature and salinity ranges for growth, flagella number and motility, pigmentation and the precise array of carbon sources that allow growth on minimal medium. C. litoralis $\mathrm{KT} 71^{\mathrm{T}}$ has the very distinctive properties of synthesizing Bchl $a$ and growing photoheterotrophically at low organic nutrient concentrations that are not possessed by strain $7 \mathrm{SM} 29^{\mathrm{T}}$.

Thus, we conclude that strain $7 \mathrm{SM} 29^{\mathrm{T}}$ represents a novel species of the genus Haliea, for which the name Haliea mediterranea sp. nov. is proposed.

\section{Description of Haliea mediterranea sp. nov.}

Haliea mediterranea (me.di.ter.ra'ne.a. L. fem. adj. mediterranea pertaining to the Mediterranean Sea).

Cells are Gram-negative, short bacilli, $0.4-0.5 \mu \mathrm{m}$ wide and 1.1-1.3 $\mu \mathrm{m}$ long, and motile by means of one, two or three polar flagella. Grows on marine agar as regular, pale-yellow colonies. Grows at $15-40{ }^{\circ} \mathrm{C}$, but not at 4 or $45{ }^{\circ} \mathrm{C}$. Growth of cells requires $\mathrm{Na}^{+}$and is enhanced by the addition of marine salts: good growth is obtained with $3.5-120 \mathrm{~g}$ marine salts $1^{-1}$, but no growth occurs with $180 \mathrm{~g} \mathrm{l}^{-1}$. Strictly chemoheterotrophic aerobe; no fermentative growth. No Bchl a. Oxidase- and catalase-positive. Reduces nitrates to nitrites but not to $\mathrm{N}_{2}$. Does not produce indole from tryptophan, arginine dihydrolase, lysine decarboxylase, ornithine decarboxylase or urease. Hydrolyses aesculin, DNA, casein, gelatin, starch and 
Tween 80, but not lecithin, alginate or agar. Carbon sources that sustain growth in BMA are preferentially organic acids and amino acids: acetate, pyruvate, propionate, butyrate, 3-hydroxybutyrate, L-alanine, L-arginine, Laspartate, L-glutamate, L-levcine, L-lysine, L-threonine and putrescine. Carbohydrates are not generally used, although weak growth is observed with amygdalin, cellobiose, salicin, D-glucuronate, DL-lactate, L-tyrosine and 4-aminobutyrate. No growth is observed with L-arabinose, Dfructose, D-galactose, D-glucose, $N$-acetyl-D-glucosamine, maltose, lactose, melibiose, D-mannose, L-rhamnose, Dribose, sucrose, trehalose, D-xylose, glycerol, myo-inositol, D-mannitol, D-sorbitol, citrate, fumarate, D-galacturonate, D-gluconate, D-glycerate, malate, 2-oxoglutarate, D-saccharate, succinate, trans-aconitate, glycine, L-citrulline, Lhistidine, L-ornithine, L-sarcosine or L-serine. In API ZYM tests, positive for alkaline phosphatase, esterase lipase (C8) (weak), leucine arylamidase, valine arylamidase, acid phosphatase, naphthol-AS-BI-phosphohydrolase and $\mathrm{N}$ acetyl- $\beta$-glucosaminidase (weak). In API $20 \mathrm{NE}$ tests, positive for reduction of nitrate to nitrite, hydrolysis of aesculin and assimilation of caprate and negative for production of indole, arginine dihydrolase and urease, fermentation of glucose, hydrolysis of gelatin and ONPG and assimilation of D-glucose, L-arabinose, D-mannose, Dmannitol, $N$-acetyl-D-glucosamine, maltose, D-gluconate, adipate, citrate, malate and phenylacetate. In Biolog GN2 MicroPlates after $48 \mathrm{~h}$, oxidizes Tweens 40 and 80, pyruvic acid methyl ester, acetic acid, $\alpha$-hydroxybutyric acid, propionic acid, alaninamide, L-alanine, L-alanyl glycine, L-asparagine, L-glutamate, glycyl L-aspartic acid, glycyl Lglutamic acid, hydroxy-L-proline, L-leucine, L-proline and phenylethylamine. Polar lipids include phosphatidylglycerol, diphosphatidylglycerol and phosphatidylethanolamine. The respiratory lipoquinone is Q-8. The major cellular fatty acids are monounsaturated $\mathrm{C}_{16}-\mathrm{C}_{18}$ compounds and the major hydroxylated fatty acid is $\mathrm{C}_{11: 0} 3$ $\mathrm{OH}$. The DNA $\mathrm{G}+\mathrm{C}$ content of the type strain is $62.1 \mathrm{~mol} \%$.

The type strain is 7 SM $29^{\mathrm{T}}\left(=\right.$ CECT $7447^{\mathrm{T}}=$ DSM $\left.21924^{\mathrm{T}}\right)$, isolated from seawater of the western Mediterranean Sea.

\section{Acknowledgements}

This work was supported by project CGL2005-02292 to M. J.P. (Spanish Ministerio de Educación y Ciencia). M. C. M. has a contract and J. P. has a postgraduate fellowship with the University of Valencia under the PTA and FPU programmes, respectively (Spanish Ministerio de Educación y Ciencia). We thank I. Galán-Chilet for technical support.

\section{References}

Arahal, D. R., Sanchez, E., Macian, M. C. \& Garay, E. (2008). Value of $r e c N$ sequences for species identification and as a phylogenetic marker within the family 'Leuconostocaceae'. Int Microbiol 11, 33-39.

Baumann, P. \& Baumann, L. (1981). The marine gram-negative eubacteria: genera Photobacterium, Beneckea, Alteromonas, Pseudomonas and Alcaligenes. In The Prokaryotes, vol. II, pp. 13021331. Edited by M. P. Starr, H. Stolp, H. G. Trüper, A. Balows \& H. Schlegel. Berlin: Springer.

Heimbrook, M. E., Wang, W. L. L. \& Campbell, G. (1989). Staining bacterial flagella easily. J Clin Microbiol 27, 2612-2615.

Ludwig, W., Strunk, O., Klugbauer, S., Klugbauer, N., Weizenegger, M., Neumaier, J., Bachleitner, M. \& Schleifer, K.-H. (1998). Bacterial phylogeny based on comparative sequence analysis. Electrophoresis 19, 554-568.

Ludwig, W., Strunk, O., Westram, R., Richter, L., Meier, H., Yadhukumar, Buchner, A., Lai, T., Steppi, S. \& other authors (2004). ARB: a software environment for sequence data. Nucleic Acids Res 32, 1363-1371.

Macián, M. C., Arahal, D. R., Garay, E., Ludwig, W., Schleifer, K. H. \& Pujalte, M. J. (2005). Thalassobacter stenotrophicus gen. nov., sp. nov., a novel marine $\alpha$-proteobacterium isolated from Mediterranean sea water. Int J Syst Evol Microbiol 55, 105-110.

Ortigosa, M., Garay, E. \& Pujalte, M.-J. (1994). Numerical taxonomy of aerobic, Gram-negative bacteria associated with oysters and surrounding seawater of the Mediterranean coast. Syst Appl Microbiol 17, 589-600.

Spring, S., Lünsdorf, H., Fuchs, B. H. \& Tindall, B. J. (2009). The photosynthetic apparatus and its regulation in the aerobic gammaproteobacterium Congregibacter litoralis gen. nov., sp. nov. PLoS One 4, e4866.

Takaichi, S., Furihata, K., Ishidu, J. \& Shimada, K. (1991). Carotenoid sulphates from the aerobic photosynthetic bacterium, Erythrobacter longus. Phytochemistry 30, 3411-3415.

Urios, L., Intertaglia, L., Lesongeur, F. \& Lebaron, P. (2008). Haliea salexigens gen. nov., sp. nov., a member of the Gammaproteobacteria from the Mediterranean Sea. Int J Syst Evol Microbiol 58, 12331237.

Urios, L., Intertaglia, L., Lesongeur, F. \& Lebaron, P. (2009). Haliea rubra sp. nov., a member of the Gammaproteobacteria from the Mediterranean Sea. Int J Syst Evol Microbiol 59, 1188-1192.

Yan, S., Fuchs, B. M., Lenk, S., Harder, J., Wulf, J., Jiao, N.-Z. \& Amann, R. (2009). Biogeography and phylogeny of the NOR5/ OM60 clade of Gammaproteobacteria. Syst Appl Microbiol 32, 124139. 